\title{
RESISTENCIAS Y REIVINDICACIONES SOCIALES. CONTEXTUALIZACIÓN DEL AMPARO A LOS DERECHOS HUMANOS DESDE LAS COMUNIDADES
}

\author{
RESISTENCES AND SOCIAL CLAIMS. CONTEXTUALIZATION OF THE \\ HUMAN RIGHTS PROTECTION FROM THE COMMUNITIES
}

Por: Hingrid Camila Pérez Bermúdez ${ }^{1}$

Angie Marcela Santana De Ángel ${ }^{2}$

Recibido: 18 de mayo de 2019 - Aprobado: 10 de octubre 2019

El derecho de soñar no figura entre los treinta derechos humanos que las Naciones

Unidas proclamaron a fines de 1948. Pero si no fuera por él, y por las aguas que da de beber, los demás derechos se morirían de sed.

Eduardo Galeano

\section{RESUMEN}

Como líderes y lideresas de un Estado Social de Derechos y desde un revisionismo jurídico, emprendemos una postura que proclama la salvaguarda de los derechos humanos y su efectividad desde un campo importante de la teoría crítica del derecho alternativo y esta, repercute de manera positiva en la interculturalidad, desde la cual se debe construir el derecho. Una sociedad garantista que renace y se replantea desde la posibilidad de buscar, no en la norma, sino en la participación, una artesanía de garantismo. Por lo tanto, el presente artículo manifiesta la intención de deconstruir la ley y forjarla desde abajo, desde las comunidades, desde sus identidades, desde lo que hace parte del ser.

Palabras clave: Comunidades, derechos humanos, interculturalidad, identidad, luchas sociales.

\footnotetext{
ABSTRACT

As leaders of a Social State of Law from a legal revisionism point of view, we undertake a position that proclaims the safeguarding of human rights and its effectiveness from an important field of the critical theory of alternative law and this has a positive

${ }^{1}$ Abogada, Especialista Justicia Constitucional y Tutela Jurisdiccional de los Derechos - Universidad de Pisa, Conciliadora en Derecho, Diplomado en Docencia Universitaria. Cursando estudios de Maestría en Derechos Humanos- Universidad Pedagógica y Tecnológica de Colombia. Cursando Doctorado en Derecho Procesal Contemporáneo Universidad de Medellín. Docente e Investigadora de la Fundación Universitaria de San Gil UNISANGIL

${ }^{2}$ Estudiante noveno semestre del Programa de Derecho - Fundación Universitaria de San Gil UNISANGIL. Miembro del Semillero de Investigación Ad Astra Per Áspera. Monitora - auxiliar de investigación.
} 
impact on the interculturality, from which the right law should be built. A guarantee society that is reborn and is reconsidered from the possibility of seeking, not in the norm, but in participation, a guarantee artisanship. Therefore, this article expresses the intention to deconstruct the law and forge it from below, from the communities, from their identities, from what is part of human being.

Key words: Communities, human rights, interculturality, identity, social struggles.

\section{INTRODUCCIÓN}

Se han consolidado luchas con ideas, con palabras, con la percepción que desde diversos enfoques se atiende al significado de la justicia; se han restringido derechos y asimismo hemos sido fuente de empoderamiento que revelan una batalla contra el abuso del poder y la hegemonía de los gobiernos por detener procesos de heterogeneidad. Referirnos a teorías sobre derechos humanos, que sean estructuradas desde una visión propia de las comunidades, sus culturas e idiosincrasias.

No podemos hablar de Derechos Humanos sin mencionar a las comunidades que recrean escenarios participativos y democráticos; no podremos hablar de Derechos Humanos solo cuando consideramos que un país ha ratificado una Convención que los promueve; no podremos hablar de Derechos Humanos si consideramos que solo desde arriba, desde las instituciones, se pueden legitimar al plasmarlos en un documento que funge como ley. Y menos aún podremos hablar de verdaderas garantías a Derechos Humanos si no revisamos, desde abajo, las propias necesidades que tienen los pueblos, que un día abatidos por conflictos, quisieron reconstruir territorios y fortalecer las comunidades de paz, de participación, de igualdad, de derechos.

Las conquistas desde abajo, desde las sociedades, desde sus luchas, resistencias y reivindicaciones, han sido las más grandes manifestaciones y proclamaciones de Derechos Humanos. A pesar de encontrar instrumentos internacionales y locales que promulgan el reconocimiento de libertades, han sido inobservados por las autoridades competentes, accionando a su vez vulneraciones sobre los mismos.

Por consiguiente, desde lo intercultural, se plantea una política participativa construida desde cada sociedad, que atienda particularmente a las necesidades de las mismas y permita, legitimar sus acciones en razón al desarrollo social y armónico de sus pueblos ${ }^{3}$.

Asimismo, a través de estos ejercicios comunitarios y democráticos, promover la participación, desde la cual se adhieren los Derechos Humanos, ya que, si hablamos de escenarios democráticos y comunitarios, se vinculan directamente cada una de las garantías de derechos, y finalmente las voces de pobladoras y pobladores no sería opacada.

${ }^{3}$ Desde una perspectiva crítica y deconstructiva ¿cómo se podría engranar el desarrollo social y armónico de los pueblos, que determine la realización de sus derechos y geste un discurso contra-legalcentrista? 


\section{Hacia una teoría deconstructiva de los Derechos Humanos}

Retomar lo olvidado para retornar hacia los procesos de transición del ser humano, hacia la declaratoria no de victoria sobre los conflictos, sino de libertad frente a los derechos que por siglos se han reclamado y siguen siendo el punto de discusión ante los gobiernos hegemónicos, ha de ser de las principales pretensiones manifestadas desde los diferentes movimientos sociales, constituidos a favor de una sola lucha por reconstruir sobre lo destruido y tener memoria por lo olvidado. ¿De qué unidad se trata cuando abordamos las luchas personales y colectivas desde el reconocimiento, de las resistencias y reivindicaciones de los pueblos, los territorios que habitan y las comunidades que conforman o a las cuales pertenecen o asumen su pertenencia?

Sobre los Derechos Humanos se ha hablado y escrito desde hace varios siglos, mujeres y hombres quienes desde sus imaginarios han movilizados sus voces en espacios donde también se efectiviza la resistencia, han sido los promotores del revisionismo de derechos y de políticas que deben replantearse desde las voces de las pobladoras y los pobladores, desde las diferencias que les habitan y los territorios que llevan inscritos en sus cuerpos.

Boaventura de Sousa Santos, críticamente refiere que:

La gran mayoría de la población mundial no es sujeto de derechos humanos, sino el objeto de los discursos de derechos humanos. Por tanto, hay que comenzar por preguntarse si los derechos humanos son eficaces para la lucha de los excluidos, los explotados y los discriminados, o si, por el contrario, la hacen más difícil. En otras palabras, ¿la hegemonía de la que goza hoy el discurso de los derechos humanos es el resultado de una victoria histórica o, por el contrario, de una derrota histórica? (Sousa Santos B, 2014, pág. 23)

Deconstruimos las categorías, no para hablar de subversión, sino para repensar lo formulado y reformularlo, para enfocar el derecho, no desde un punto homogéneo, sino desde una visión heterogénea de los intereses, las sociedades, las culturas y los territorios que movilizan al ser humano.

Hablar de Derechos Humanos y de las herramientas efectivas que se necesitan para seguir promoviendo estas luchas por el reconocimiento de derechos, insta a determinar que "los derechos humanos son considerados como movimiento social, político e intelectual, así como (su) teoría propiamente dicha. Su determinación básica, a lo largo de su historia, consiste en su carácter emancipatorio (resistencia al abuso del poder, reivindicación de libertades, regulación garantista por parte del Estado) su sustrato político indeleble la exigencia y afirmación de reconocimiento" (Arias Marín, 2013, p.98).

Referirnos a planteamientos del ser humano, relacionados con el derecho y la efectividad de las garantías propias, genera una brecha con un abismo infinito entre la teoría y el pragmatismo, que, si bien los dos planteamientos coadyuvan hacia el fortalecimiento y reconocimiento de los Derechos 
Humanos, aún persisten los espacios de discriminación, inequidad, desigualdad, conflictos, guerras y masacres, que atentan contra la vida y la dignidad humana.

Por lo tanto, los Derechos Humanos, han sido el resultado de grandes luchas, que, aunque desde diversos contextos han reivindicado derechos y parten de las necesidades propias de los territorios, fortalecen y armonizan los ordenamientos internos hacia la consolidación de una política NO discriminatoria. "La lucha por la dignidad humana es la razón y la consecuencia de la lucha por la democracia y por la justicia” (Herrera Flores, S. F, p.14).

A partir de la fundamentación de los Derechos Humanos, persisten planteamientos, con enfoques que entretejen y divergen a los contextos sociales, políticos y económicos de cada país, en el que se ha alzado una voz de lucha y firmeza por la proclamación de los derechos y la no más violencia hacia los mismos.

Se entiende aquí por fundamento de los Derechos Humanos la realidad o realidades, de carácter social o intersubjetivo, que proporcionan a los mismos la consistencia necesaria para que puedan ser reconocidos, promovidos y garantizados en su conjunto, de forma indivisible e interdependiente, y puedan proyectarse hacia un desarrollo siempre abierto y perfectible (Torrado Lima, 2012, pág. 225).

No se trata entonces de una interpretación o comprensión filosófica sobre el ser humano y su incipiente pronunciamiento sobre los derechos que se tienen, es referenciar conductas propias que encaminen el actuar hacia la imperante protección sobre la dignidad humana.

¿Qué son los derechos en un Estado Social de Derecho? Más allá de elucidaciones sobre lo que es y no es, sobre la verdad y la mentira, lo justo y lo injusto, los derechos han sido el despertar de pobladoras y pobladores, frente a siglos de sometimiento por políticas que, dentro de los criterios de los legisladores, no devenían estructuras que permitieran hablar del ser humano, como sujeto de derechos y garantías globales.

La universalidad de los derechos humanos es la negación de la discriminación en todas sus manifestaciones. Esta práctica es un modo de ser enraizado en la sociedad que todos los Estados se han comprometido a erradicar mediante la aplicación del derecho internacional de los derechos humanos con criterio universal (Galvis L., 2015, pág. 65)

Más que cuestionar el revisionismo histórico que formó los Derechos Humanos y los traslada hacia la positivación, es decir, hasta la promulgación de una ley que confiere garantías y obligaciones; hacemos hincapié en la materialización propia de estos en los diferentes Estados que proclaman salvaguardarlos, y reflexionar, si al final de todo el entramado jurídico, no basta con pretenderlos, sino incluirlos en una disposición normativa, para que realmente se hable de efectividad. 
Nuestro compromiso, como personas que reflexionan sobre -y se comprometen con- los derechos humanos, reside en poner las "frases" a las prácticas sociales de individuos y grupos que luchan cotidianamente para que esos "hechos" que se dan en los contextos concretos y materiales en que vivimos puedan ser transformados por otros más justos, equilibrados e igualitarios. Por eso, la verdad la ponen los que luchan por los derechos. A nosotros nos compete el papel de poner las frases. Y este es el único modo de ir complementando la teoría con la práctica y las dinámicas sociales: clave del criterio de verdad de toda reflexión intelectual (Herrera Flores, s.f, pág. 20)

Las diferentes aristas de transición, las prácticas que conducen a la reclamación de derechos, revisten un sentido potencial frente al autoritarismo y abuso del Estado, los movimientos sociales desde sus rasgos heterogéneos, han proclamado una voz vehemente contra instituciones que, de manera excluyente, arremeten contra los intereses de grupos que exhortan a la defensa de los derechos humanos. Y es aquí donde encontramos dos caminos que diferencian el contenido propio de los derechos, un primer momento, desde el derecho positivo y lo que las instituciones han intentado rescatar hacia el culto de la ley, y que, si no está en una disposición normativa, el derecho sencillamente no existe. Así como el reformular lo planteado y concretar derechos desde abajo, desde lo que hacen las comunidades interesadas en reparar lo destruido y ser artesanas de procesos transicionales de garantías, como segunda elocución.

Refiriéndonos a lo señalado, los Derechos Humanos, vistos desde la institucionalidad, emergen a través del Sistema Mundial a cargo de la ONU (Organización de las Naciones Unidas) y la Declaración Universal de Derechos Humanos, la cual proclama que "todos los seres humanos nacen libres e iguales en dignidad y derechos y, dotados como están de razón y conciencia, deben comportarse fraternalmente los unos con los otros" (1948). El compromiso ratificado por los países, contempla los deberes imprescindibles de estos, por efectivizar, materializar, restablecer y fundamentar la protección hacia los DDHH. A su vez, desde el Sistema Regional, la OEA (Organización de Estados Americanos), nacen dos organismos importantes como lo son la Corte Interamericana de Derechos Humanos y la Comisión Interamericana de Derechos Humanos, tribunales que actúan en razón y función principal a la protección de la Convención Americana sobre Derechos Humanos (en adelante CADH) o Pacto de San José de Costa Rica.

El ratificar la competencia contenciosa de la Corte Interamericana, por parte de los países, obedece a modificar cualquier normatividad interna, sin importar el rango en el que se encuentre, cuando esta última contraríe los Derechos Humanos contemplados a través del instrumento internacional ${ }^{4}$. Figura conocida desde el Sistema Interamericano como control de convencionalidad, que para

\footnotetext{
${ }^{4}$ Artículo 2. Deber de adoptar disposiciones de derecho interno.

Si el ejercicio de los derechos y libertades mencionados en el artículo 1 no estuviere ya garantizado por disposiciones legislativas o de otro carácter, los Estados Partes se comprometen a adoptar, con arreglo a sus procedimientos constitucionales y a las disposiciones de esta Convención, las medidas legislativas o de otro carácter que fueren necesarias para hacer efectivos tales derechos y libertades.
} 
algunos críticos irrumpe con la soberanía y la libre autodeterminación de cada Estado al momento de promulgar las leyes que bien sean para su beneficio, ya que serían expulsadas del ordenamiento interno al no dialogar de manera positiva con la Convención Americana. Sin embargo, si es sobre temas de Derechos Humanos, ¿no se hace necesaria la consolidación de un organismo competente que funja como veedor de estos derechos?

Por otra parte, vistos los Derechos Humanos desde abajo, desde las comunidades que han sido afectadas por las guerras, desde los pobladores que el conflicto se les ha llevado a sus seres queridos, desde las desigualdades sociales, políticas, económicas, desde la perspectiva de inequidad, de pobreza, de resistencia, ahí radican las verdaderas luchas que se proclaman y se levantan a favor de los derechos de los niños, niñas, adolescentes, adultos mayores, mujeres y hombres.

Por esta razón, nuestra teoría crítica de los derechos humanos trabaja con la categoría de deberes autoimpuestos en las luchas sociales por la dignidad, y no de derechos abstractos ni de deberes pasivos que se nos imponen desde fuera de nuestras luchas y compromisos (Herrera Flores, s. f, pág. 16)

Cuando hablamos de Derechos Humanos, no podemos solo pensar que es un contenido normativo de mecanismos que garantizan derechos e imponen obligaciones a los Estados, así como a los particulares; refiérese a temas de Derechos Humanos, permite visualizar no una estatura positiva, sino las resistencias lideradas por los pueblos, que, abatidos por diferentes vejámenes, y a pesar de cualquier circunstancia negativa, reconstruyen escenarios de paz, de igualdad, participación, e inclusión social.

\subsection{Repensemos el derecho. Procesos de reconstrucción de libertades y garantías.}

Contemplar desde el derecho positivo normas que defiendan los Derechos Humanos, no arremete de manera genérica a que estos están siendo efectivizados dentro de los territorios, ni hace parte de la máxima expresión universal de los mismos. Visualizar alternativas que desdibujan los panoramas legales impuestos desde tiempos remotos y considerar alternativas para su efectividad, permite pronunciar nuevos vocablos de garantías en las sociedades. Entonces, ¿Cómo repensar el derecho para que cumpla sus fines de protección?

Las legislaciones que conocemos, además de ser antiquísimas, fueron diseñadas bajo unos contextos ajenos y anteriores a las necesidades propias como actuales de cada territorio. Además, son remitidas de otros lugares, bajo costumbres e idiosincrasias que difieren notablemente de las nuestras. Entonces, ¿Qué tan eficaz es una norma que pregona derechos ajenos a los propios? Con esto, no se quiere afirmar que para cada país deben existir componentes de derechos únicos e irrepetibles, pero sí que los mismos, se diseñen bajo estructuras sólidas, proporcionales y remitidos directamente del sentipensar propio de las pobladoras y pobladores. 
Las teorías críticas sobre el derecho alternativo han permitido observar la ley, desde la construcción social, con las características propias que evocan a la interculturalidad de los territorios desde donde se reformulan. "Se trata de repensar un proyecto social y político contrahegemónico, capaz de reordenar las relaciones tradicionales entre Estado y sociedad, entre el universalismo ético y el relativismo cultural, entre la razón práctica y la filosofía del sujeto, entre el discurso de integración y el de la diversidad, entre las formas convencionales de legalidad y las experiencias plurales no-formales de jurisdicción" (Wolkmer, s.f, pág. 143)

La participación ciudadana no se consume con elegir y ser elegido, o ser parte de partidos políticos que desarrollan la democracia representativa, los fines propios de la participación devienen del compromiso por ser líderes y lideresas de diferentes espacios propositivos de cambios, donde se permita concertar un ideal y respaldarlo desde los territorios y las necesidades que de manera individual estos presentan.

El pluralismo jurídico "comprometido con la alteridad y con la diversidad cultural se proyecta como instrumento contrahegemónico, por cuanto moviliza concretamente la relación más directa entre nuevos sujetos sociales y poder institucional, favoreciendo la radicalización de un proceso comunitario participativo"(Wolkmer, s.f., p.145), un derecho vivo, radical, que se forja no desde arriba, como una ley propuesta por una autoridad legitimada para hacerlo, sino desde abajo, a partir de propuestas definidas por las comunidades, los intereses que prestan al interior de cada uno de estas y la cultura que evoca a la consecución de sociedades afines.

¿Pero cómo interpretar el derecho desde la cultura? Dilucidamos sobre las garantías que proporcionan las leyes al exigir un derecho, pero aseveramos sobre las posibilidades de implementar las normas desde una construcción en la cual se reconoce el valor ético de las diferencias, las diversidades y los conflictos, así como de las resistencias y reivindicaciones de las poblaciones ancestralmente excluidas; desde una visión cada vez más amplia de lo que cada territorio es, lo que son sus raíces, las identidades y valores que repercuten en el tejido social que vislumbra sobre lo quebrantado y propone una estabilidad acorde con el ser propio de cada imaginario social y cultural. "El discurso jurídico se construye en un entretejido de discursos sociales diversos, aludidos y eludidos en cada tramo de esa construcción; y no por azar. El derecho no deviene ni de la pura razón, ni de dios; es parte de la cultura, es contingente y cambiante. Es opaco, las ficciones lo atraviesan y su trama es la de un relato peculiar que constituye realidades y sujetos, que legitima o deslegitima pedazos del mundo, que naturaliza y declara verdaderos solo lo que incluye en su texto bajo determinadas formas" (Ruiz A., s.f pág.16)

Si el derecho perse solo tiene razón para ordenar la sociedad y promover la convivencia armónica de la misma, ¿Cómo podríamos ampliar y efectivizar estos fines alejados de la hegemonía de la ley? Debido a que, la estructura normada es ajena a los compromisos de los territorios, y lo que 
identifica la resistencia pura y propia de cada región, que desde su compromiso por la madre tierra, ha forjado la idiosincrasia que abandera los procesos culturales; finalmente estos procesos no pueden ser desconocidos por la disposición legal. "Lo que el derecho puede concebir en nuestras posiciones depende de las controversias. En este sentido, las controversias crean el derecho. El derecho en sí mismo es origen de controversias futuras ya que crea nuevas pretensiones o nuevas bases sobre las que soportar antiguas fundamentaciones" (Chase O, 2011, pág. 64)

Redefinir los escenarios que han sido colonizados por la ley, desde un marco intercultural, alejados de la visión eurocéntrica y fortalecidos a lo que en definitiva es la esencia propia del ser humano inmerso en las comunidades, redefiniría la propuesta legislativa, que para esta oportunidad sería construida desde los propios albores sociales y participativos de mujeres y hombres que integran los pueblos, y ya no desde un escritorio que desconoce los intereses generales contrapuestos hacia los particulares.

Una teoría crítica del derecho ha de ser sociológica, o al menos sociologista, en el sentido de no limitarse a una comprensión del derecho ni meramente dogmática, ni formalista, ni reducida al derecho del Estado. Ha de estar por el contrario abierta a estudiar las diferentes legalidades, alegalidades e ilegalidades entrecruzadas presentes en las experiencias sociales. La concepción moderna del derecho, positivista jurídica en términos generales, identifica de forma reduccionista el derecho con el derecho del Estado y asume su estudio en unos términos formalistas que legitiman una supuesta despolitización del derecho (Lema Anón, 2018, pág. 26)

Dos casos, de cientos, se referencian a continuación, donde a pesar de los elementos subversivos que contiene la guerra y los pleitos que son ajenos a las comunidades, se ha reconstruido, no la ley, sino la participación social y el tejido roto y rasgado que dejaron los intereses de unos cuantos.

\subsection{Asociación de Trabajadores Campesinos del Carare (ATCC).}

Josué, Manuel, Héctor, Llanero, Simón, Oswaldo, Rosita, Excelino, Juan Roy, Miguel Ángel, Sylvia, y Alejandro compartían varias cosas que les unieron entre sí para siempre. Vivían a lo largo del Río Carare en una zona conocida como La India, en las selvas de Magdalena Medio en el país de Colombia. Eran campesinos. Se consideraban gente corriente. Y afrontaban un reto extraordinario: cómo sobrevivir a la perversa violencia de los numerosos grupos armados que atravesaban sus tierras y les exigían lealtad.

A finales de los 60, el movimiento guerrillero de orientación izquierdista FARC (Fuerzas Armadas Revolucionarias de Colombia) entró en los territorios de Carare. Tras él llegó la respuesta militar del Gobierno nacional, que fue incrementándose. Incapaces de perjudicar o eliminar la influencia de los movimientos guerrilleros en la región, los terratenientes, en muchos casos conjuntamente con los militares, organizaban en secreto y financiaban privadamente a los "paras", grupos armados 
de vigilantes de derecha, que pronto adquirieron mayor independencia. Se luchaba no solo por la tierra, en la cual habían establecido sus hogares las primeras familias campesinas que llegaron, y contra los impuestos de guerra extraoficiales, sino incluso por obtener su lealtad. (...) Tales eran las realidades a las que se enfrentaban Josué, Héctor, Manuel y las demás personas campesinas de la región en medio del silencio. Un campesino de mediana edad, Josué, habló desde la multitud y desde su corazón. Su discurso fue tan memorable que a día de hoy todavía se encuentran personas en La India que pueden recitar palabra por palabra su respuesta al capitán: "Hablas de perdón, pero ¿qué tienes que perdonarnos? Sois vosotros los que habéis violado. Nosotros no hemos matado a nadie. Nos queréis dar millones en armas pagadas por el Estado, sin embargo, no facilitáis ni el mínimo crédito para nuestras necesidades agrarias.

(...) Unos días después, esa misma semana, un grupo de veinte dirigentes campesinos decidió jugar la última carta: Practicarían la resistencia civil sin armas. Según lo definió uno de ellos, "ese día decidimos hablar por nosotros". En las semanas y meses subsiguientes, organizaron uno de los más insólitos y espontáneos procesos de transformación vistos en Colombia en 50 años.

Formaron la Asociación de Trabajadores Campesinos de Carare (ATCC). Su primera acción fue romper el código de silencio. Desarrollaron formas de organización y participación. La participación estaba abierta a cualquier persona. La cuota de entrada era un sencillo compromiso: Tu vida, no tu dinero. Se resumía en la frase "moriremos antes que matar" (Lederach, s. f)

Resistencias ante los vejámenes y masivas vulneraciones a Derechos Humanos que se presentaban sobre la región del Magdalena Medio, y es que a pesar de que sus vidas estaban en juego, admitieron que sólo con las acciones y la palabra, se podrían silenciar los rifles, se podían generar espacios de participación, de manifestación y de lucha, todo por la reivindicación a derechos como la vida, la salud, la familia, la dignidad humana. Así, desde este primer panorama, se evidencia que a pesar de la existencia de indefinidos requerimientos legales que protegen al ser humano, fue desde abajo, desde los ideales de unas cuantas personas, que, perseguidas por el sometimiento de la guerra, alzaron sus voces y fueron escuchadas.

\subsection{Mujeres que hacen historia (Centro Nacional de Memoria Histórica)}

La historia que se hará referencia es la de Margarita, una joven que el conflicto armado le dejó heridas profundas y rasgos de violencia, que, a pesar de los sufrimientos sobrellevados, su carácter la llevaron a liderar importantes procesos de participación y restitución de tierras. Margarita nació

\footnotetext{
${ }^{5}$ Según el Centro Nacional de Memoria Histórica, en el informe "El Orden desarmado. La resistencia de la Asociación de Trabajadores Campesinos del Carare (ATCC) señala: Con la no violencia como telón de fondo, la Asociación fue consolidando otro conjunto de principios que establecieron un norte para la organización y fueron completando el conjunto de criterios orientadores bajo los cuales sus miembros actuaban. En particular, el lema de la ATCC: "Por el derecho a la vida, la paz y el trabajo", es un aforismo que condensa los elementos rectores del campesinado movilizado en resistencia y tal vez uno de los pocos elementos discursivos compartidos sin variaciones (menores o mayores) a través de los individuos que participan en el proceso de resistencia civil.
} 
en 1956 en la zona bananera del departamento de Magdalena en el seno de una familia de escasos recursos, (...) tuvo que sacarle el quite al hambre durante muchos años. Su vida condensa, como pocas otras, la vitalidad, la desenvoltura y la voluntad de autonomía de muchas mujeres, y a su vez los desafíos y los traumas que ellas confrontan en un contexto adverso donde se combinan y refuerzan prácticas de una dominación masculina brutal ejercida tanto por hombres de su entorno cotidiano como por integrantes de grupos armados (...) Su relato también permite resaltar cómo no sólo los hombres luchan por transformar la falta de oportunidades en las que sus existencias transcurren, sino también las mujeres.

Como prueba de que 'lo que se hereda no se hurta', Margarita se repone de estos traumas y, siguiendo el ejemplo de su madre, se une, ya de 30 años, a la ANUC en 1986. Lo hace en una época distinta a la de su madre en varios aspectos, contradictorios entre sí. Es en este contexto que Margarita se destaca como lideresa social en la ANUC y es nombrada en 1987 presidenta de uno de sus comités municipales. A pesar de sus anteriores experiencias dolorosas con los hombres, Margarita tiene gratos recuerdos de esas épocas de militancia, que son prueba de su enorme fortaleza y su capacidad de recomponer una relación fundada en la confianza frente al género masculino. La vida de Margarita ilustra como pocas la perseverancia de las mujeres para alcanzar una vida mejor para ellas y sus familias. Hoy Margarita sigue luchando para recuperar su predio y alcanzar las reparaciones a las que tiene derecho por las infracciones a sus derechos que sufrió a manos de los distintos actores armados. Es una mujer admirable porque, no obstante, el sufrimiento que ha vivido, conserva una vitalidad y una gracia que a veces, cuando no se encuentra sumida en un momento de depresión, derrocha con generosidad sobre los que la rodean. (CNMH, Mujeres que hacen historia)

Esta historia, de una mujer valiente, una mujer luchadora, que sin importar las consecuencias que se presentasen y los rasgos de violencia marcados en su cuerpo, lideró procesos con la ANUC y reivindicó sus territorios, sus costumbres, culturas e idiosincrasias, con empuje y fortaleza. Un importante escenario de restablecimiento de derechos, desde las comunidades, porque solo estas conocen sus propios compromisos por el país, para entretejer lo desintegrado y recordar lo que no se ha querido revelar.

Resistencia que se presenta desde la protección al ambiente, desde la reivindicación de estrategias que les permitan gozar por mucho más tiempo de la naturaleza y del derecho al trabajo, al sustento, a la alimentación, el derecho a vivir y desarrollar al máximo sus calidades de vida.

Esto es lo que se presenta, de manera breve, desde los territorios, una proclamación de lucha, de intereses generales, de reconocimiento y restablecimiento por los Derechos Humanos, que, aunque constituidos a través de diversos instrumentos, se han reivindicado a partir del compromiso de personas líderes y lideresas, impulsadas por concretar acuerdos comunitarios, participativos que 
representan las verdaderas intenciones de sus poblaciones.

Pensemos, por ejemplo, en el lugar que ocupan en relación con ello, la escuela rural, la junta de acción comunal, las asociaciones de vecinos, el consejo comunitario, la organización campesina, la asociación de productores, la zona de reserva campesina, las comunidades de paz, los espacios humanitarios, las justicias comunitarias, las formas de conciliación en equidad, entre muchos otros. Estos bienes son expresión de lo que Ashutosh Varshney (2002) denomina "sistemas institucionalizados de paz" es decir, "compromisos intercomunales que moderan las tensiones y previenen la reactivación de la violencia” (Jaramillo, Castro y Ortiz, 2018, pág. 27).

Como corolario de lo expuesto, se trata de dar una revisión sobre el derecho y los derechos, que se aproxime más a los intereses de cada región, a sus culturas y lo que se destaca en cada una de estas, donde la palabra identidad no repercute bajo una singularidad y homogenización, sino por el contrario, se compone de pluralidades, pluriversos y heterogeneidades propias de los territorios de derechos. "La idea de soberanía comunitaria nos sitúa, además, frente al reconocimiento de la existencia de muchos ejercicios locales de democracia y maneras sensibles y adecuadas de construcción de nexos con institucionalidades y gobernanzas estatales o globales" (Jaramillo, Castro y Ortiz, 2018, pág. 27).

Dentro del Estado Social de Derecho al que hacemos parte y desde la regulación imperante de la sociedad participativa en las decisiones estatales, se vislumbra frente al caos de la injusticia, una esperanza de efectivización de derechos que se relaciona con la cultura; "las instituciones comunitarias son más que reglas de juego abstractas, en esa medida fungen como entramados cotidianos de prácticas sociales, estrategias de poder que se convierten con el tiempo en movilizadoras de la memoria organizativa local““(Jaramillo, Castro y Ortiz, 2018, pág. 28).

La cultura, lo que somos, lo que construimos desde las identidades, así como en lo que nos transformamos, hace parte de un todo movilizador de imaginarios sociales, donde sí se requiere cumplir las expectativas de las normas y los componentes propios que distinguen los requisitos de efectividad, no se puede alejar la cultura del derecho, porque de así serlo, hablaríamos bajo tonalidades divergentes incapaces de proclamar gritos de justicia.

\section{CONCLUSIONES}

Hablamos de Derechos Humanos desde diferentes lenguajes, culturas, países, fronteras, nos referimos a categorías, fundamentaciones, teorías y sus prácticas, pero ¿Cuándo hablamos de Derechos Humanos? ¿Cuándo se entienden efectivizados? Dos interrogantes bastante complejos para el siglo en el que nos encontramos.

Han pasado 70 años desde que diferentes Estados proclamaron la Declaración Universal de Derechos Humanos y 49 años desde que se promulgó la Convención Americana sobre Derechos Humanos o 
Pacto de San José de Costa Rica, sin embargo, de manera infortunada, estos esfuerzos desde arriba, la institucionalidad, no han logrado permear las masivas vulneraciones a derechos, debido a que según informes del Centro Nacional de Memoria Histórica, entre los años 1980 y 2013, se han presentado alrededor de 1982 masacres en el territorio colombiano. Entonces, ¿Cuándo hablamos de Derechos Humanos?

A medida que van pasando los años, se insiste en generar dentro de los Estados, medidas que no solo impulsen el reconocimiento de una norma que ampare derechos, sino que, a su vez, implementen estrategias efectivas que permitan su materialización.

Por tal razón, a partir de las rupturas discursivas sobre la dignidad humana que con ocasión a las guerras se han presentado al interior de las comunidades, es que renacen los nuevos ejercicios locales de participación, así como se evidenció en los casos presentados, y debe ser desde el empoderamiento comunitario y el derecho intercultural, que se cree un híbrido entre las instituciones locales, departamentales, nacionales y las instituciones comunitarias, que a través de sus luchas, libertades y derechos, acompañan los procesos de paz territorial y Derechos Humanos.

Así las cosas, no podremos dejar a un lado el gran esfuerzo que han realizado las comunidades por construir al tejido social y reivindicar derechos, por lo tanto, es necesario apostarle a la democracia comunitaria a través de una política de resistencia, construcción y reparación, amparando todas las identidades, lo que somos, en lo que se transforma el hombre dentro de su cultura, como guía sustancial en la ejecución de estas garantías.

Mejorada la política participativa de las comunidades, desde la cultura y revisadas, mediante procesos de concertación que permitan apalabrar los conflictos vividos en las comunidades cuando se trata de definir prioridades, podríamos, en palabras de Lederach, considerar que "fue la oportuna aparición por azar venturoso de la imaginación moral en los asuntos humanos” (Lederach, 2007).

\section{REFERENCIAS BIBLIOGRÁFICAS}

Arias Marín A. (2013). Contribución a una teoría crítica de los Derechos Humanos. Revista de Derecho Uned, Núm. 13, 2013.

Boaventura de Sousa S. (2014). Derechos Humanos democracia y desarrollo. ISBN 978-95858464-6-3 versión digital.

Boacentura de Sousa Santos. (2018) Construyendo las epistemologías del sur. Antología esencial volumen II. Parte III “Derecho para otro mundo posible” Presentación - Carlos Lema Añón.

Declaración Universal de Derechos Humanos (1948). Recuperado de: http://www.un.org/es/ universal-declaration-human-rights/ 
Centro Nacional de Memoria Histórica. (2011). El orden desarmado. La resistencia de la Asociación de Trabajadores Campesinos del Carare (ATCC). Recuperado de: www.centrodememoriahistorica. gov.co

Chase O. (2011). Derecho cultura y ritual. Sistemas de resolución de controversias en un contexto intercultural. ISBN: 978-84-9768-869-7

Centro Nacional de Memoria Histórica. (2011). Mujeres que hacen historia, Tierra, cuerpo y política en el Caribe colombiano. ISBN: 978-958-758-347-2

Convención Americana sobre Derechos Humanos (1969). Recuperado de: https://www.oas.org/ dil/esp/tratados_b32_convencion_americana_sobre_derechos_humanos.htm

Galvis L., (2015) Comprensión de los Derechos Humanos. ISBN: 958-9136-17-6

Herrera Flores J. (s. f.). La reivindicación de los Derechos Humanos. ISBN (13): 978-84-6122958-1

Jaramillo Jefferson M., Fabio Saúl Castro Herrera y Daniel Ortiz Gallego. (2018). Instituciones comunitarias para la paz en Colombia. Esbozos teóricos, experiencias locales y desafíos sociales. Universidad Nacional de Colombia.

Lima Torrado J. (2012). El fundamento de los Derechos Humanos. Programa de Mestrado em Ciência Jurídica da UENP.

Lederach. (2007). La imaginación moral. El arte y el alma de la construcción de paz

Ruiz A. E., (s.f) Cuestiones acerca de mujeres y derecho.

Wolkmer A. (s.f) Pluralismo jurídico, derechos humanos y globalización. Universidad Federal de Santa Catarina. 